единицы запоминаются намного легче, чем чтение, даже с объяснениями, грамматического правила в учебнике. [5]

Подводя итоги урока (части урока), преподаватель может предложить учащимся в качестве домашнего задания написать небольшой рассказ на какую-либо тему с обязательным использованием выученных ими конструкций, которые были предъявлены преподавателем. На следующем уроке этот рассказ каждый учащийся, например, может прочитать вслух для последующего обсуждения в группе.

Таким образом, преподаватель на уроке русского языка в иностранной аудитории может способствовать оптимизации и интенсификации учебного процесса и поднять его на качественно новый уровень, при этом не забывая решать повседневные вопросы и проблемы.

Правильная и продуманная организация процесса обучения является залогом эффективной работы преподавателя и учащихся. Занятия русского языка не должны быть перегружены новыми лексическими и грамматическими единицами. Преподаватель не должен забыть, что новые лексические единицы необходимо предъявлять на основе уже изученной грамматики. Новая грамматика должна даваться на основе уже знакомой учащимся лексики.

$$
* * *
$$

1. Касарова В.Г., Ежовкина О.А. Пути предупреждения речевых ошибок иностранных учащихся / Международное образование и сотрудничество. Сборник научных трудов. - М.: МАДИ, 2016. C. $36-42$.

2. Касарова В.Г., Ежовкина О.А. Работа над тавтологическими речевыми ошибками на уроках русского языка как иностранного // Сборник материалов V Международной научно-практической конференции «Профессионально направленное обучение русскому языку иностранных граждан. М.: МАДИ, 2017. - С .211-214.

3. Касарова В.Г. Речевые ошибки иностранных студентов и их причины // В сборнике «Гуманитарные науки». - М.: МАДИ, 2003. № 21.- С. 24-28.

4. Л.С. Кременецкая Проектирование содержания обучения иностранных граждан из стран СНГ на довузовском этапе в техническом вузе. Автореферат дис. ... кандидата педагогических наук / Московский государственный агроинженерный университет им. В.П. Горячкина. - М., 2013.

5. Л.С. Кременецкая Проектирование содержания обучения иностранных граждан из стран СНГ на довузовском этапе в техническом вузе. Диссертация ... кандидата педагогических наук: 13.00 .08 / Московский государственный агроинженерный университет им. В.П. Горячкина. - М., 2013.

\title{
Касарова В.Г., Кременецкая Л.С. \\ К вопросу об изучении собирательных числительных на уроках русского языка как иностранного (из опыта работы)
}

\author{
МАДИ \\ (Россия, Москва)
}

doi: 10.18411/lj-06-2021-175

\section{Аннотация}

В статье авторы рассматривают одну из самых сложных тем для иностранных учащихся - собирательные числительные. Авторы статьи считают, что данной теме надо уделать достаточное внимание, чтобы предупредить ошибки в речи иностранных учащихся. В статье даны примеры таких числительных, приведены способы их объяснения иностранным учащимся. Для изучения такой сложной темы необходимо большое количество примеров, в статье подобные примеры разбираются достаточно подробно, показывается их использование в речевых ситуациях.

Ключевые слова: иностранные учащиеся, собирательные числительные, примеры, русский язык как иностранный, оптимизировать работу, использование числительных, речевые ситуации. 


\section{Abstract}

In the article, the authors consider one of the most difficult topics for foreign students collective numbers. The authors of the article believe that this topic should be given sufficient attention to prevent mistakes in the speech of foreign students. The article provides examples of such numerals, provides ways of explaining them to foreign students. In the process of studying such a complex topic, a large number of examples are needed; in the article, such examples are analyzed in sufficient detail, shows their use in speech situations.

Keywords: foreign students, collective numerals, examples, Russian as a foreign language, optimize work, use of numerals, speech situations.

Изучение числительных в иностранной аудитории всегда является достаточно сложной темой. При объяснении этой темы преподавателю русского языка как иностранного приходится учитывать очень много различных нюансов. Обычно на занятиях больше времени уделяется для изучения порядковых и количественных числительных. Собирательные числительные практически не упоминаются. И в этом состоит большое упущение, поскольку понимание и правильное употребление данной грамматической категории также необходимо.

У обучающихся могут возникнуть речевые, языковые ошибки при изучении данной темы, и преподаватели должны быть к этому готовы. [1] Ошибки необходимо предупреждать и исправлять. [2] Чтобы оптимизировать работу над ошибками при изучении данной темы в иностранной аудитории, преподавателю русского языка необходимо объяснить систему использования количественных и собирательных числительных. Остановимся подробнее на возможной методике объяснения этой трудной грамматической темы.

Необходимо сразу объяснить учащимся, когда можно и когда нельзя использовать собирательные числительные, показать систему их употребления, а также дать ряд примеров их использования. Для начала нужно их познакомить с данной грамматической категорией и дать список собирательных числительных, существующих в русском языке, прочитать их, проставить ударение. Можно ограничиться несколькими примерами. Думаем, что для знакомства можно написать десять правильных форм, объяснив, что не все формы используются часто. Например, «двое», «трое», «четверо», «пятеро», «шестеро», «семеро», «восьмеро», «девятеро», «десятеро». Нужно обратить внимание иностранных учащихся, что собирательные числительные «восьмеро», «девятеро», «десятеро» используются достаточно редко в нашей речи.

Иностранным учащимся необходимо объяснить, что после собирательных числительных мы всегда используем родительный падеж множественного числа. Например, «двое инженеров», «трое докторов», «четверо преподавателей», «пятеро котят», «шестеро детей» и т.д. Но для чего нам нужны эти числительные? Таким вопросом, иной раз, задаются иностранные учащиеся, поскольку у нас уже есть количественные числительные: «два», «две», «три», «четыре», которые используются в родительном падеже единственного числа, и «пять», «шесть», «семь», «восемь», «девять», «десять», которые употребляются в родительном падеже множественного числа.

Сразу следует подчеркнуть, что мы всегда можем наравне использовать следующие сочетания числительных с существительными: «два инженера» или «двое инженеров». Но при этом можно использовать «две студентки» и нельзя использовать слово «студентка» с собирательными числительными. Данную грамматическую категорию необходимо объяснять исключительно на примерах, поскольку мы 
используем собирательные числительные в некоторых случаях. Иногда мы можем наравне использовать количественные и собирательные числительные, и значение словосочетаний будет одинаковым. А иногда мы можем использовать только сочетания с количественными числительными или только с собирательными числительными. Поэтому в русском языке собирательные числительные очень нужны и важны и иностранным учащимся их использование необходимо объяснять. Собирательные числительные нужно знать и понимать, и уделять им должное внимание.

Необходимо довести повторить с обучающимися, что с количественными числительными «два», «три», «четыре» используется родительный падеж единственного числа, а с количественными числительными «пять», «шесть», «семь», «восемь», «девять», «десять» родительный падеж множественного числа. И сравнить с собирательными числительными, где всегда будет родительный падеж множественного числа существительного и прилагательного.

Иностранные учащиеся необходимо выучить правило использования количественных и собирательных числительных. Нельзя использовать собирательные числительные с женским родом. Например, мы можем сказать «две девушки», «три кошки», «четыре сумки», но не можем использовать слова «девушка», «кошка», «ручка» в сочетании со словами «двое», «трое», «четверо».

Также нельзя использовать собирательные числительные с существительными среднего рода. Можно сказать «два места», «три задания», «четыре яблока», но нельзя использовать слова «место», «задание» в сочетании с числительными «двое», «трое», «четверо».

Нельзя использовать собирательные числительные с неодушевленными существительными мужского рода. Мы можем сказать «два стула», но нельзя при этом использовать числительное «двое» в сочетании со словом «стул».

Можно использовать собирательные числительные с одушевленными существительными мужского рода. Можно сказать «два студента и «двое студентов», значения при этом будут одинаковыми. Можно использовать собирательные числительные со словами «дети», «люди», «ребята». Например, «двое людей», «трое ребят», «пятеро детей». Но с этими словами нельзя использовать количественные числительные. В данной ситуации мы можем сказать «два ребенка» или «двое детей». Или «два человека», «двое людей» или «двое ребят».

Мы также можем использовать собирательные числительные с местоимениями «нас», «вас», «их». Например, «нас двое», «вас трое», «их четверо», «нас было пятеро», «вас будет двое». «Сколько вас?» - «Нас трое».

Также можно использовать собирательные числительные с существительными, которые в русском языке мы используем только во множественном числе. Например, «ножницы», «часы», «брюки», «джинсы», «сутки». Например, мы можем сказать «двое ножниц», «трое часов», «четверо брюк», «двое джинсов», «двое суток». С данными словами мы не можем использовать количественные числительные. Со словом «часы» (Под часами мы понимаем прибор для измерения времени) мы можем также добавлять слово «штука», например, «нет пяти штук часов».

Мы используем собирательные числительные с парными предметами, в значении «столько-то пар». Парные предметы всегда используются парой, их всегда должно быть два или две. Например, «перчатки», «носки», можно сказать «две перчатки» или «двое перчаток», «два носка» или «двое носков». В данной ситуации оба варианта возможны, мы можем использовать и собирательные, и количественные числительные. «Нормативным является сочетание «двое брюк», а не «две пары брюк», вызывающее представление о четырех предметах, так как брюки считают не на пары, а 
на штуки. Сочетания «пара брюк», «пара ножниц» имеют разговорный характер.» [3: 61]

Мы можем использовать собирательные числительные с молодыми животными. Например, «трое котят» или «три котенка», «пятеро щенят» или «пять щенков». Здесь также возможно использование количественных и собирательных числительных.

«Предпочтительно употребление собирательных числительных с субстантивированными прилагательными словами мужского рода, например, «двое прохожих», «трое больных» и т.д.» [3: 61]

Необходимо объяснить учащимся, что собирательное числительное не могут входить в составные числительные, которые должны быть образованы только из одних количественных числительных. Мы можем сказать «двое суток», но если нам необходимо использовать числительное «двадцать два» со словом «сутки», то возникает проблема. Числительные «двадцать два», «двадцать три», «двадцать четыре» нельзя сочетать со словами, у которых нет формы единственного числа, которые используются только во множественном числе. В подобных ситуациях необходимо слово «сутки» заменить на слово «день», например, «двадцать два дня», или изменить конструкцию фразы, например, «Каникулы продолжались в течение двадцати двух суток».

Следует также все время напоминать иностранным учащимся, что если у них возникают сомнения по поводу использования той и иной конструкции, то необходимо посмотреть соответствующее правило в справочной литературе, либо заменить незнакомую им конструкцию на уже известную для них. Хотя мы считаем, что если учащиеся не будут пытаться искать новые формы выражения собственных мыслей в речи, то их речевое и языковое развитие замедлится. [4: 211]

Следует подчеркнуть, что в процессе предъявления данной грамматической категории в иностранной аудитории необходимо использовать большое количество примеров, чтобы показать все возможные варианты применения теории в практических ситуациях. «С помощью подобных заданий иностранные учащиеся учатся самостоятельно писать небольшие сочинения» [5: 73] на основе пройденной на занятии темы. Можно сначала на уроке устно выполнить под руководством возможный вариант домашнего задания, проанализировать возможные речевые конструкции, содержащие собирательные числительные. Это предлагается сделать, «чтобы показать учащимся модель для письменного задания, а также обеспечить более прочное усвоение навыков речевой деятельности.» [5: 73]

$$
* * *
$$

1. Касарова В.Г., Ежовкина О.А. Пути предупреждения речевых ошибок // В сборнике «Международное образование и сотрудничество. Сборник материалов V Международной научнопрактической конференции «Профессионально направленное обучение русскому языку иностранных граждан». - М.: ТехПолиграфЦентр, 2016. - С.35-42.

2. Касарова В.Г. Речевые ошибки иностранных студентов и их причины // В сборнике «Гуманитарные науки». - М.: МАДИ, 2003. № 21.- С. 24-28.

3. Розенталь Д.Э. Говорите и пишите по-русски правильно. - М.: Айрис-Пресс, 2007. - 182 c.

4. Касарова В.Г., Ежовкина О.А. Работа над тавтологическими ошибками на уроках русского языка как иностранного // В сборнике «Международное образование и сотрудничество. Сборник материалов V Международной научно-практической конференции. - М.: МАДИ, 2017. - С.211-214.

5. Касарова В.Г., Кременецкая Л.С. Использование практикума «Гуляем по Москве» на занятиях по русскому языку как иностранному для совершенствования навыков речевой деятельности // В сборнике «Международное образование и сотрудничество. Сборник материалов VI Международной научно-практической конференции. - М.: МАДИ, 2019. - С.71-75. 